\title{
Technical requirements for translucent structures of schools and kindergartens
}

\author{
Aleksandr Konstantinov ${ }^{1,}{ }^{*}$, Elena Romanenkova ${ }^{1}$ and Margarita Borisova ${ }^{1}$ \\ ${ }^{1}$ Moscow State University of Civil Engineering, 129337 Yaroslavskoe shosse, 26, Moscow, Russia
}

\begin{abstract}
The article presents some features of the translucent structures design of schools and kindergartens. The analysis of technical requirements for translucent structures of schools and kindergartens was represented. Based on a review of the typical composition of the premises of schools and kindergartens, it was found that different technical requirements should be established for translucent structures installed in rooms of various functional purposes and operating conditions. It was determined that the existing construction practice doesn't take into account the differentiation of requirements for translucent structures of various premises of schools and kindergartens, and their design, as a rule, is taken to be the same for the entire construction objects. In future, it leads to disruption of the normal operation of the facility (especially in terms of ensuring normal temperature and humidity conditions and natural lighting of the premises). The features of the replacement of translucent structures in reconstructed schools and kindergartens were considered. It has been revealed that the use of modern types of translucent structures of standard construction (first of all, PVC window units) in the reconstruction leads to a significant decrease in the indicators of natural room lighting. Ways to solve this problem were given. Moreover, perspective directions for future research of the issue under consideration were considered.
\end{abstract}

\section{Introduction}

Functional and technical requirements of windows of civil buildings. Buildings of general education schools (hereinafter referred to as schools) and pre-school educational institutions (hereinafter referred to as kindergartens) are now an integral part of any residential area of a city or township. They are intended for the temporary stay of children, so any question of their design, construction and operation should be approached with special care. At the same time, it is obvious that every technical solution incorporated into a school or kindergarten project should provide not only minimum regulatory requirements for the comfort and safety of children's stay in such establishments, but also, if possible, exceed them in order not only to preserve, but also to increase health of the younger generation. Modern projects of newly erected, as well as reconstructed buildings of schools and kindergartens are implemented taking into account the above provisions. This is especially clearly expressed in the much more expanded role of translucent structures

\footnotetext{
* Corresponding author: apkonst@yandex.ru
} 
(windows, doors, glass facades and roofs, etc.) in the formation of the architectural appearance of such objects (see figure 1). The objective of the current study was the analyze the technical requirements for the windows of kindergartens and schools, taking into account the functional purpose of their rooms, as well as the relationship analysis of the windows technical characteristics and their impact on the provision of comfortable conditions in the rooms.

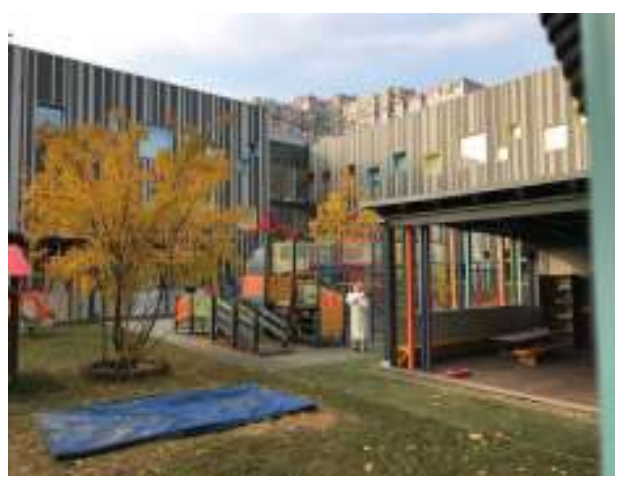

a)

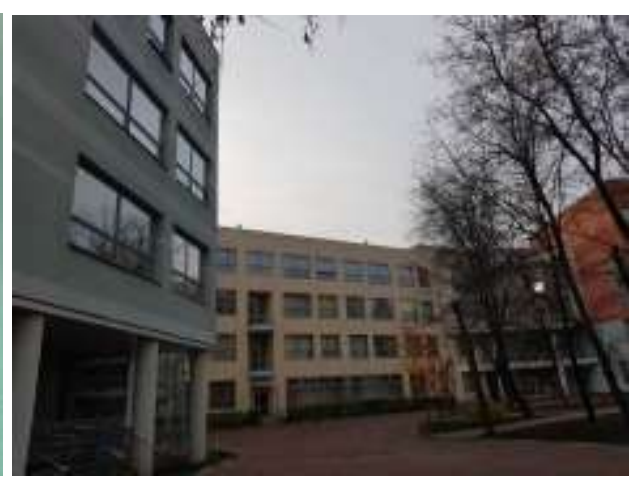

b)

Fig. 1. Examples of the use of translucent structures in modern projects of schools and kindergartens. A - The newly erected kindergarten building. B. The newly erected school building.

The translucent structures of any schools and kindergartens have to provide [1-7]:

- preset level and uniformity of natural room lighting;

- the required insolation duration of the premises;

- tightness of the outer shell of the building (air- and water permeability) and minimal heat loss (energy efficiency);

- specified temperature and humidity conditions of the premises in winter and summer periods of operation (in winter there is no condensation on the internal surfaces of translucent structures, in summer there is no overheating of the premises under the influence of solar radiation);

- sound insulation from outdoor noise (primarily transport);

- natural ventilation of the premises (airing);

- safety and convenience of daily use;

- safety and convenience of periodic maintenance;

- protection against unauthorized access to the premises as a result of hacking.

It is obvious that the selection of constructive solutions for translucent structures of schools and kindergartens at the stage of their architectural and construction design should accounts the above requirements.

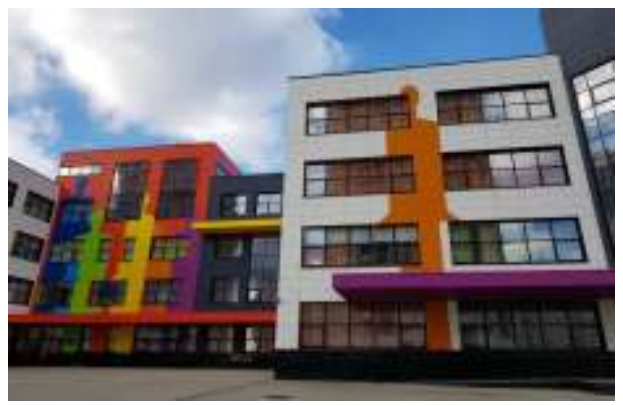

Fig. 2. Examples of incorrect construction of windows in schools and kindergartens. Lack of opening upper transoms. 
Existing standards [8] containing requirements for translucent structures do not comprehensively address these aspects. It leads to the fact that often in the projects of schools and kindergartens incorrect technical solutions for translucent structures are laid, especially in terms of providing safety and maintenance requirements (see figure 2).

\section{The influence of the functional purpose of schools and kindergartens buildings on the technical solution of translucent structures}

A distinctive feature of modern schools and kindergartens is the significant differentiation of their premises for functional purposes. In particular, the kindergarten buildings are characterized by the division into the following premises:

- main premises (group, play, sleeping rooms), designed to accommodate and provide children in groups;

- additional facilities (gymnasium and music hall, swimming pool, classrooms, changing rooms), intended for short-term use by pre-school groups;

- ancillary facilities that provide the operation of the main and additional premises (communication rooms - corridors and vestibules, administrative rooms, technical and utility rooms, etc.).

Hereinafter, the question of kindergarten windows design is considered, since this type of translucent structures is currently most often used for glazing of similar objects, and most of the requirements for kindergarten glazing can be extended to schools.

It is obvious that it is necessary to present your technical requirements to the windows of each of the above premises. First of all, these requirements are determined by the functional purpose of the room and the required parameters of its microclimate. Based on this, when designing glazing schools and kindergartens for each type of premises should be taken appropriate windows constructs. In the existing practice of design and construction, this, as a rule, doesn't happen, and the design of the windows is assumed to be uniform for the whole object. At the same time the minimum requirements for windows are regulated, which are regulated by the basic regulatory documents. This approach is the simplest, but not rational, because in most cases it doesn't allow to provide all project requirements for window designs.

The basic requirement that determines the choice of window design is to provide thermal protection and energy efficiency of the construction object. One of the indicators of compliance with the thermal protection is to provide that the set temperature on the opaque elements of the window units and on the glazing surface under the given design conditions of temperature (set external and internal air temperature and humidity of the internal air). Apparently, that for premises of various functional purposes (for example, sleeping rooms and swimming pools in kindergartens) the requirements for normalized parameters of the microclimate will be differ significantly. In particular, for the case under consideration, the required heat transfer resistance of kindergarten windows calculated for the conditions of Moscow (according to Russian Standard SP 50.13330.2012 Thermal performance of the buildings) will be respectively $0.51\left(\mathrm{~m}^{2} \mathrm{~K}\right) / \mathrm{W}$ (bedroom with an internal air temperature $+20{ }^{\circ} \mathrm{C}$ ) and $0.65\left(\mathrm{~m}^{2} \mathrm{~K}\right) / \mathrm{W}$ (pool with the internal air temperature $+30{ }^{0} \mathrm{C}$ ). Such a significant difference (more than 20\%) will require the use of various window constructions as in the part of the profile system and in the part of the design of insulation glass units.

For premises located on the first floors of kindergartens, increased requirements are made to exclude the possibility of unauthorized access. Currently, the most effective solution for protection against burglary is the use of protective window units, which make it 
possible to walk back the using of external metal lattices. For tamper-resistant windows it is necessary to use insulation glass units with external glass, which made of triplex In turn, it leads to decrease in the overall light transmission of the window, and, as a result, to the need for additional justification for providing a given level of natural lighting. An important event that provides the given sanitary and hygienic conditions inside the premises of kindergartens is their periodic airing. For this purpose, kindergarten windows can be equipped with opening transoms and sashes. Besides, opening sashes are necessary for the periodic maintenance of windows (washing). At the same time, in order to avoid children to fall out through open windows, the possibility of their opening by children should be limited. For do this, you must use the "children's" locks.

\section{Features of replacement windows in the reconstruction of schools and kindergartens}

During reconstruction / overhaul of schools and kindergartens, main attention is paid to improving the energy efficiency of facilities. One of the most effective ways to improve the energy efficiency of a building is to replace old windows with new ones $[9,10]$. Replacing windows in the event of adopting their rational design also allows to qualitatively improve sound insulation of premises, as well as their breaking resistance, which is especially important for large cities with a high level of sound pollution and difficult crime conditions.

In the process of appointing a new window design solution, it is necessary to take into account that, in most cases, modern standard designs of PVC and aluminum window units have a significantly lower overall light transmission coefficient. Compare the light transmission of old and new window units design. In most cases, for the conditions of Moscow for the glazing of schools and kindergartens used paired wooden blocks with double glazing. The calculated value of the light transmission of such windows is 0.6 and more. For similar PVC window units with a filling of two-chamber energy-efficient doubleglazed windows, the approximate light transmission will be no more than 0.50 . This is mainly due to the fact that the height of the combinations of the profile elements "frame + sash", "impost + sash" of modern window systems made of PVC and aluminum significantly exceeds similar combinations of old wooden paired window units. Thus, when we will replace old windows with new ones in schools and kindergartens without additional activities, the parameters of natural lighting of rooms will be significant changed.

\section{Results}

The natural lighting calculation results of a typical school rooms (room dimensions $6 \times 9 \mathrm{~m}$; room height $3.6 \mathrm{~m} ; 3$ windows $2,1 \times 2,4 \mathrm{~m}$ ) shows that the replacement of old windows during the school reconstruction the coefficient of natural light is significantly reduced (see Table 1).

The natural lighting of the premises is also reduced due to measures to warm the facades of buildings $[11,12]$. New windows are installed, as a rule, in the plane of the wall in the same position as the replaced ones. Therefore, the new window blocks after the facade insulation are significantly deepened relatively the new exterior plane of the facade, which additionally leads to a decrease in the natural lighting of the premises. However, modern technological solutions in the field of window technologies allow solving such problems. For this purpose, it is possible to use profile elements with a reduced profile height (frame, sash, impost), as well as insulation glass units with coated glass. Using the same technology of remote installation of window units in the zone of insulation will not 
only increase the natural lighting of the premises, but also increase the energy efficiency of the outer shell of the building [13-15].

Researches show that when replacing windows, there is a change in the thermal regime of the compounds of window units to the outer walls [10]. Therefore, the possibility of replacing old window units with new ones must also be justified in terms of ensuring normalized thermal protection parameters.

Table 1. Comparison of data on the calculation of natural lighting of a typical kindergarten room before and after the replacement of window units.

\begin{tabular}{|l|l|c|}
\hline No & Scheme horizontal incision on the outer wall & $\begin{array}{l}\text { The reduction of natural lighting } \\
\text { coefficient }\end{array}$ \\
\hline 1 & $\begin{array}{l}\text { Outer wall }(300 \mathrm{~mm})+\text { old wooden window } \\
\text { block }\end{array}$ & 0 \\
\hline 2 & Outer wall $(300 \mathrm{~mm})+$ PVC window block & 30 \\
\hline 3 & $\begin{array}{l}\text { Outer wall }(300 \mathrm{~mm})+\text { ventilated facade }(250 \\
\text { mm) + PVC window block }\end{array}$ & 30 \\
\hline
\end{tabular}

\section{Discussion}

Obviously, that for establish a design process for translucent structures of schools and kindergartens, it is necessary to develop specialized regulatory documents. They should systematize technical requirements for translucent structures of schools and kindergartens, as well as include recommended procedures and basic technical solutions for such structures [16]. Considering the significant differentiation of the school's and kindergarten's premises according to their functional purpose and mode of operation, it seems promising to develop adaptive window systems that allow them to change their constructive solution during the day and in the annual cycle taking into account changing external conditions and modes of operation of premises. Researches show [17-21] that when choosing windows it is necessary to additionally conduct also a multifactor analysis of their technical characteristics (light transmission, thermal protection, sound insulation, etc.).

\section{Conclusions}

A set of technical requirements for translucent structures of modern schools and kindergartens was reviewed and analyzed. It has been established that due to the significant differentiation of premises in terms of their functional purpose and mode of operation, uniform technical requirements cannot be imposed on translucent structures of schools and kindergartens. The interrelation between various technical characteristics of translucent structures and their joint influence on the provision of normalized parameters of the indoor microclimate were considered.

\section{References}

1. I. Boriskina, A. Plotnikov, A. Zaharov, Design of modern window systems for civil buildings (2008)

2. I. Boriskina, N. Shvedov, A. Plotnikov, Modern translucent constructions for civil buildings. Designer handbook (2005)

3. Z.S. Zomorodian, M. Tahsildoost, M. Hafezi, Renewable \& Sustainable Energy, Reviews 59, 895-906 (2016) 
4. D. Mumovic, J. Palmer, M. Davies, M. Orme, I. Ridley, T. Oreszczyn, C. Judd, R. Critchlow, H.A. Medina, G. Pilmoor, C. Pearson, P. Way, Building and Environment 44(7), 1466-1477 (2009)

5. L. Heschong, R.L. Wright, S. Okura, Journal of the Illuminating Engineering Society 31(2), 101 (2002)

6. V. De Giuli, O. Da Pos, M. De Carli, Building and Environment 56, 335-345 (2012)

7. A. Montazami, M. Wilson, F. Nicol, Building and Environment 52, 129-141 (2012)

8. EN 14351-1:2006+A1:2010

9. V.K. Savin, N.V. Savina, Building and reconstruction 4(60), 124-130 (2015)

10. A. Konstantinov, A. Mukhin, IOP Conference Series: Materials Science and Engineering 177(1), 012019 (2018)

11. I.A. Shmarov, V.A. Zemtsov, V.G.Gagarin, E.V. Korkina Izv. Vuzov, Tehnologija tekstil'noj promyshlennosti 4(364), 234-240 (2016)

12. V.A Zemtsov, E.V. Gagarina, Academia. Architecture and Construction 3, 472-476 (2010)

13. A. Konstantinov, T. Safiullov, IOP Conference Series: Materials Science and Engineering 365 (2), 022017 (2018)

14. F. Sierra, B. Gething, J. Bai, T. Maksoud, Energy and Buildings 142, 23-30 (2017)

15. C. Misiopecki, M. Bouquin, A. Gustavsen, B.P. Jelle, Energy and Buildings 158, 10791086 (2018)

16. T. Niernela, R. Kosonen, J. Jokisalo, Applied Energy 183, 1005-1020 (2016)

17. M. Tahsildoost, Z.S. Zomorodian, Journal of Building Physics 42(3), 336-362 (2018)

18. Z.S. Zomorodian, M. Tahsildoost, Energy and Buildings 134, 80-93 (2017)

19. J.W. Lee, H.J. Jung, J.Y. Park, J.B. Lee, Y. Yoon, Renewable Energy 50, 522-531 (2013)

20. E. Ghisi, J.A. Tinker, Building and Environment 40(1), 51-61 (2005)

21. K.K. Gorantla, S. Shaik, A.B.T.P.R. Setty, International Journal of Heat and Technology 36(3), 1121-1129 (2018) 